\title{
Instantaneous Attributes Applied to Full Waveform Sonic Log and Seismic Data in Integration of Elastic Properties of Shale Gas Formations in Poland
}

\author{
Kamila Wawrzyniak-Guz ${ }^{1, *}$ \\ ${ }^{1}$ AGH University of Science and Technology, Faculty of Geology Geophysics and Environment \\ Protection, Department of Geophysics, A. Mickiewicza Av. 30, 30-059 Krakow, Poland
}

\begin{abstract}
Seismic attributes calculated from full waveform sonic log were proposed as a method that may enhance the interpretation the data acquired at $\log$ and seismic scales. Though attributes calculated in the study were the mathematical transformations of amplitude, frequency, phase or time of the acoustic full waveforms and seismic traces, they could be related to the geological factors and/or petrophysical properties of rock formations. Attributes calculated from acoustic full waveforms were combined with selected attributes obtained for seismic traces recorded in the vicinity of the borehole and with petrophysical parameters. Such relations may be helpful in elastic and reservoir properties estimation over the area covered by the seismic survey. Key words - shale gas, Baltic Basin, full waveform sonic log, seismic attributes, elastic and reservoir properties.
\end{abstract}

\section{Introduction}

In shale gas deposits elastic and reservoir properties of rocks are one of the most significant parameters in hydrocarbon prospection. They can be derived from seismic surveys, well logging measurements or laboratory tests. However, integrated interpretation is still a challenge due to the scale dependence of geophysical parameters. Seismic attributes calculated from full waveform sonic log and from seismic data were proposed as a method that may enhance the interpretation the data acquired at various scales.

Silurian and Ordovician shales in Poland spread along the western margin of the East European Platform in Lublin, Podlasie and Baltic basins, reaching about $700 \mathrm{~km}$ in length. In this paper analysis of the Silurian (S) and Ordovician (O) shale formations from the Baltic Basin, Poland is presented. There are numerous claystones, siltstones and mudstones deposits: the Pelplin Claystone Formation (Pe Fm, S), the Pasłek Claystone Formation (Pa Fm, S) with the Jantar Bituminous Black Claystone Member ( $\mathrm{Ja} \mathrm{Mb}, \mathrm{S}$ ) and the Sasino Claystone Formation (Sa Fm, O). Other formations are marly, such as the Prabuty Marl and Claystone Formation ( $\mathrm{Pr} \mathrm{Fm}, \mathrm{O}$ ); and the other are carbonate deposits: the Kopalino Limestone Formation (Ko Fm, O).

* Corresponding author: wawrzyni@agh.edu.pl 
$\mathrm{Ja} \mathrm{Mb}$ and $\mathrm{Sa} \mathrm{Fm}$ are considered as formations with high hydrocarbon potentials. These formations are rich in organic matter and are characterized by elevated TOC content up to 7 wt.\% in investigated borehole [1] (Fig. 1).

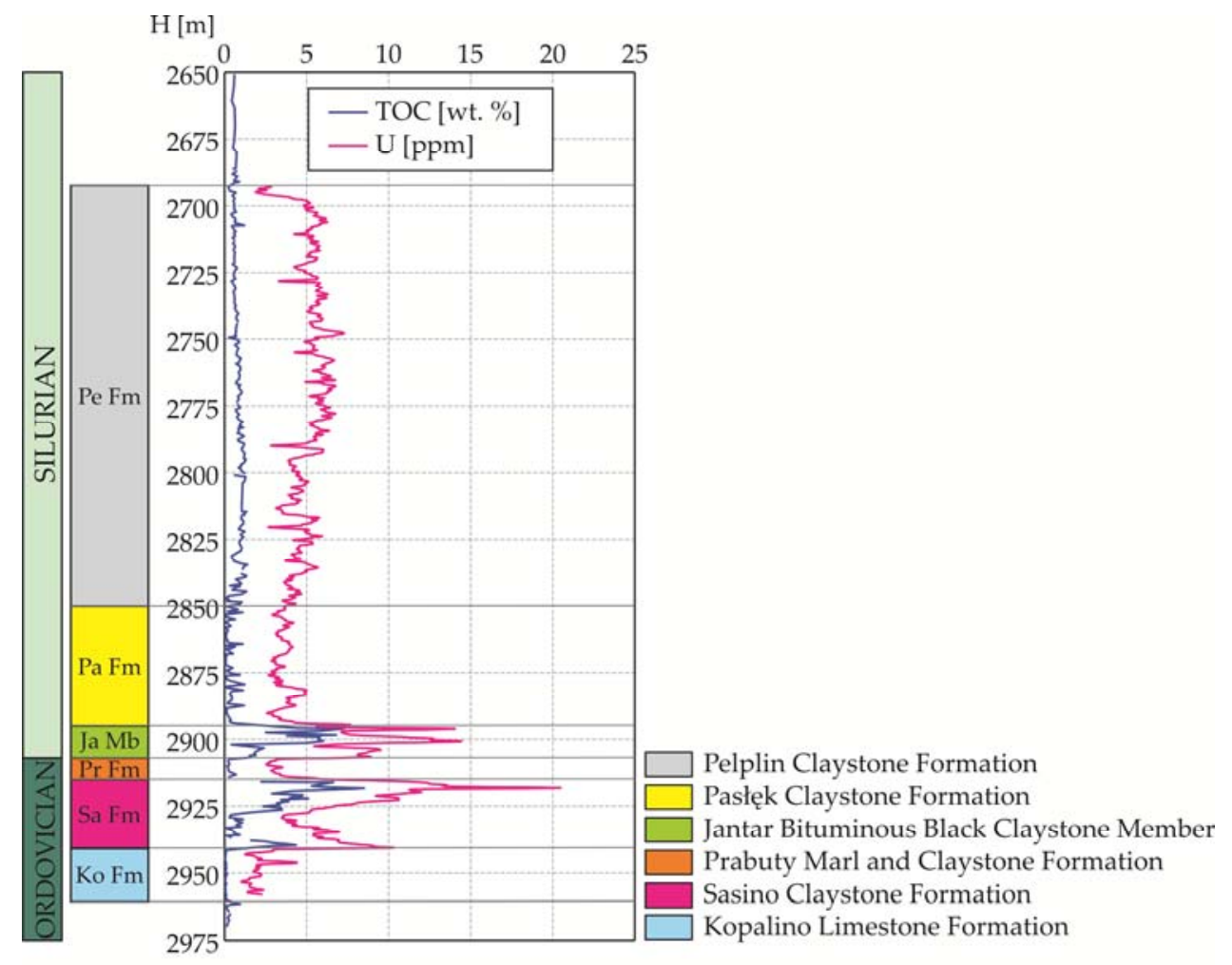

Fig. 1. TOC laboratory results and uranium concentration from spectral gamma well log in a well located in Baltic Basin, Poland (after [2])

\section{Well log and seismic data}

In this study the acoustic full waveforms recorded by the cross dipole sonic tool were used for instantaneous attributes calculations. Compressional (P), shear (S), and Stoneley (St) waves induced by the monopole transmitter were selected from the recordings.

10 seismic traces (5 Xlines and 5 Inlines) in the location of the investigated borehole were chosen for the analysis. The seismic traces were converted into depth domain with the use of P-wave sonic log corrected to the checkshot data.

\section{Methodology}

Special methodology for the calculation of attributes from acoustic full waveforms, similar to seismic attributes, was developed. The technique was previously designed for data recorded by sonic tools with monopole sources of elastic waves and successfully tested in siliciclastic and carbonate rocks of some Polish conventional hydrocarbon plays [3]. However, in this study the methodology needed to be adjusted and modified with respect to different tool design and distinct characteristic of waveforms that were recorded by Cross Dipole Wave Sonic tool (Halliburton) in shale formations from the Baltic Basin, Poland. 
The idea of was to convert acoustic log into seismic data presentation (Fig. 2). In well logging orientation the vertical axis displays the depth of the borehole (i.e. "the length of the profile"), whereas the horizontal axis shows the recording time of acoustic full waveforms. Visualization of seismic data is similar, but the horizontal axis presents the profile (f. ex. CDP traces) and the vertical axis is the recording time of the seismic traces. When the axes of acoustic full waveforms were rotated into seismic survey orientation it was possible to import the acoustic full waveforms into the seismic software, such as HampsonRussell software. Then instantaneous attributes analogous to the seismic attributes were calculated within the time windows defined separately for P, S and St waves (Fig. 3).

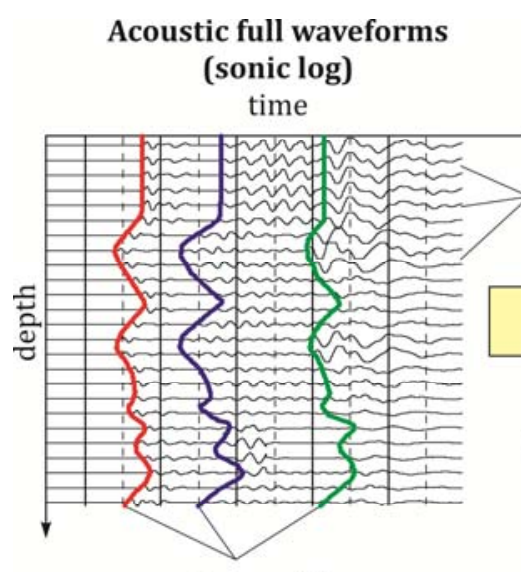

acoustic travel times
Seismic survey

(traces)

CDP

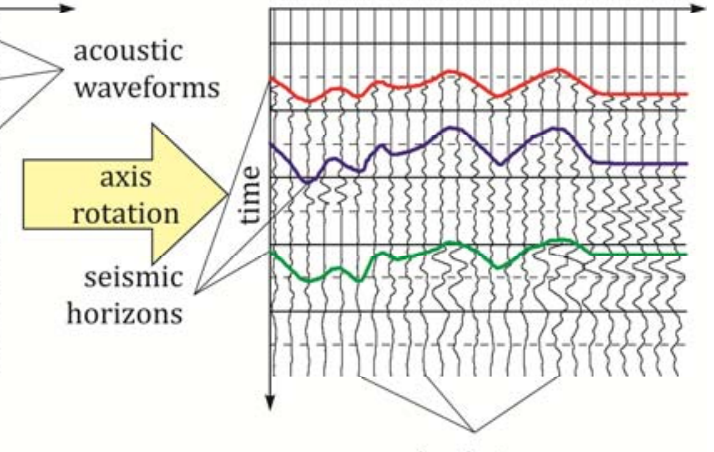

seismic traces

Fig. 2. Rotation acoustic well log data into seismic orientation.

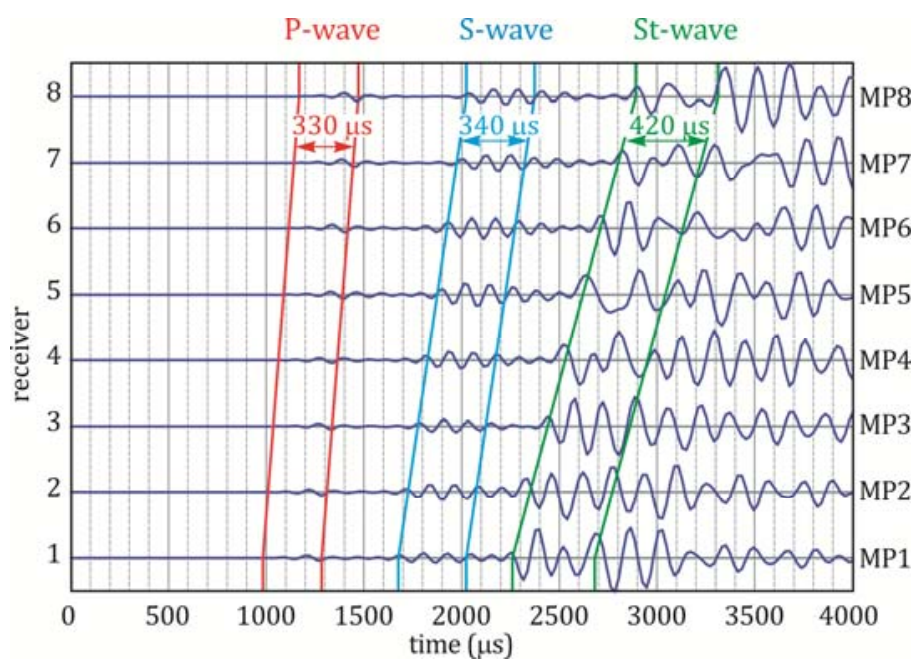

Fig. 3. Selection of $P, S \&$ Stoneley waves from the acoustic full waveforms

Attributes calculated from acoustic full waveforms were compared with the attributes obtained for seismic traces recorded in the vicinity of the boreholes. As a result, several crossplots and correlations were constructed. Such relations may be useful for lithology determination; indication of zones saturated with water and hydrocarbon and may be helpful in elastic and reservoir properties estimation over the area covered by the seismic survey. 


\section{Elastic and reservoir properties of shale formations investigated by attributes}

\subsection{Attributes applied to acoustic waves ( $P, S \& S t)$ and to seismic data}

Instantaneous attributes can enhance subtle changes of signals that were not visible at the raw recordings. Though attributes calculated in this study were the mathematical transformations of amplitude, frequency, phase or time of the acoustic full waveforms and seismic traces, they could by related to the geological factors and/or petrophysical properties of rock formations [4-6].

For P, S and Stoneley waves (that were extracted from sonic log) the following attributes were calculated: acoustic envelope (P_AE, $\left.S \_A E, S t A E\right)$, instantaneous frequency ( $P$ _nfreq, S_InFreq, St_InFreq), dominant frequency (P_DomFreq, S_DomFreq, St_DomFreq) and some combination of these attributes such as $\mathrm{P}$ and $\mathrm{S}$ acoustic envelope ratio (AE_P/S) or dominant frequency to instantaneous frequency ratio (DomFreq $\mathrm{P} / \mathrm{InFreq}_{\mathrm{C}} \mathrm{P}$ and DomFreq_S/InFreq_S).

A set of attributes calculated from seismic data was more extensive and included all complex trace attributes (AE_Seis, InFreq_Seis), P-wave impedance from seismic inversion (P-Imp_Inv) and its mathematical transformations (square, derivative, integral, logarithm), and results of spectral decompositions (f. ex. SD60_20 60Hz, window $20 \mathrm{~ms}$ ).

\subsection{Analysis of instantaneous attributes for P- and S-wave from sonic log}

Firstly, the distribution of instantaneous attributes over the formations was investigated. Figure 4 presents the histograms of P_AE, S_AE, P_DomFreq and S_DomFreq.
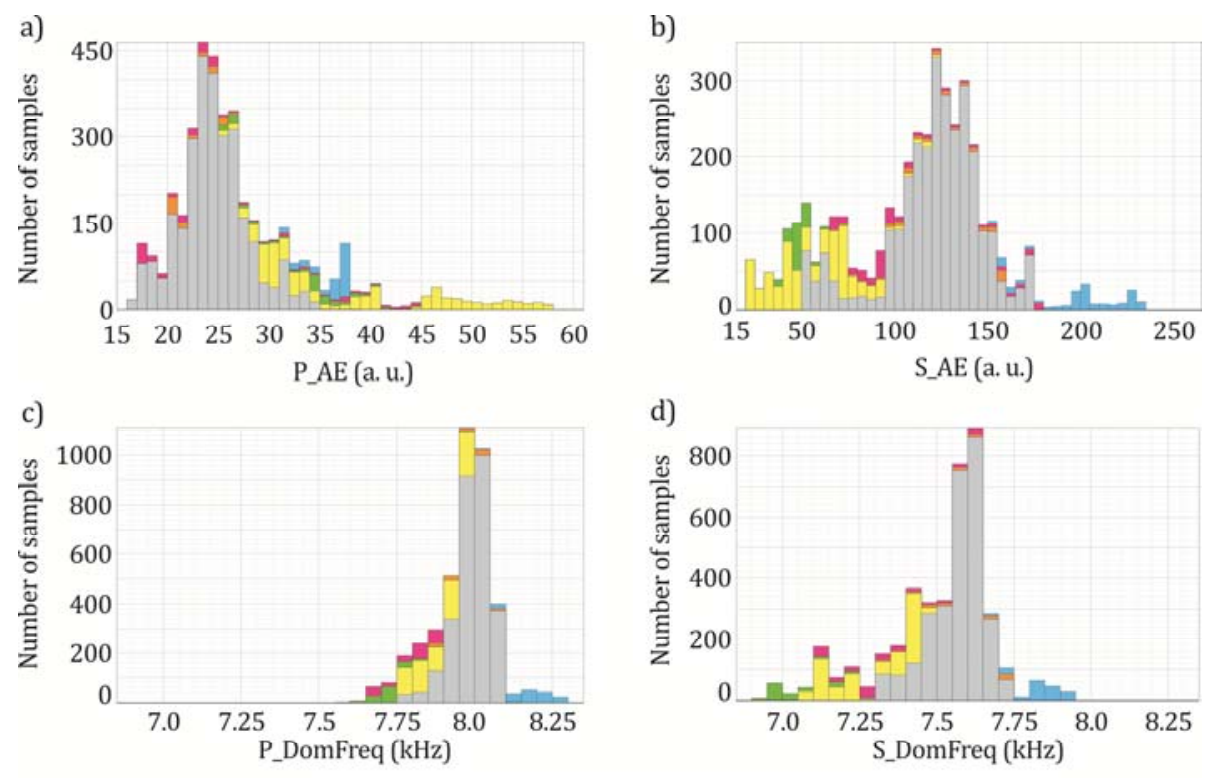

$\square$ Pe Fm $\square$ Pa Fm $\square \mathrm{Ja} \mathrm{Mb} \square$ PrFm $\square \mathrm{SaFm} \square \mathrm{KoFm}$

Fig. 4. Histograms of selected instantaneous attributes calculated from sonic logs: acoustic envelope of $\mathrm{P}$ wave (a) and $\mathrm{S}$ waves (b), and dominant frequency of $\mathrm{P}$ (c) and $\mathrm{S}$ wave (d) 
The histograms prove diversity of the shale formations. Each formation is characterized by specific range of values of calculated attributes that is listed in Table 1.

Table 1. Basic statistics of instantaneous attributes from sonic logs over investigated formations

\begin{tabular}{|l|c|c|c|c|c|c|}
\hline \multicolumn{1}{|c|}{ Statistics } & Pe Fm & Pa Fm & Ja Mb & Pr Fm & Sa Fm & Ko Fm \\
\hline \multicolumn{7}{|c|}{ P_AE (a. u.) } \\
\hline Min-max & $24.5-38.3$ & $25.5-57.3$ & $25.9-44.6$ & $20.1-26.1$ & $17.3-44.7$ & $31.8-37.8$ \\
Arith. mean & 24.5 & 38.5 & 33.2 & 22.6 & 26.5 & 36.2 \\
Std. dev. & 3.4 & 9.1 & 5.0 & 2.1 & 8.4 & 1.9 \\
\hline \multicolumn{7}{|c|}{ S_AE (a. u.) } \\
\hline Min-max & $51.2-174.4$ & $20.2-121.2$ & $35.9-64.8$ & $66.6-159.7$ & $66.3-177.7$ & $153.3-234.5$ \\
Arith. mean & 121.3 & 56.1 & 48.3 & 124.4 & 108.7 & 200.6 \\
Std dev. & 25.6 & 22.8 & 4.8 & 26.6 & 33.3 & 23.0 \\
\hline \multicolumn{7}{|c|}{ P_DomFreq (kHz) } \\
\hline Min-max & $7.88-8.10$ & $7.58-7.99$ & $7.64-7.85$ & $7.86-8.05$ & $7.67-7.89$ & $7.97-8.23$ \\
Arith. mean & 8.00 & 7.96 & 7.73 & 7.97 & 7.79 & 8.17 \\
Std. dev. & 0.06 & 0.07 & 0.05 & 0.06 & 0.08 & 0.07 \\
\hline \multicolumn{7}{|c|}{ S_DomFreq (kHz) } \\
\hline Min-max & $7.31-7.73$ & $6.97-7.46$ & $6.94-7.29$ & $7.30-7.74$ & $7.10-7.64$ & $7.68-7.94$ \\
Arith. mean & 7.57 & 7.29 & 7.05 & 7.57 & 7.34 & 7.83 \\
Std. dev. & 0.08 & 0.13 & 0.10 & 0.13 & 0.16 & 0.07 \\
\hline \multicolumn{7}{|c|}{ P_InstFreq (kHz) } \\
\hline Min-max & $7.73-7.94$ & $7.79-7.93$ & $7.70-7.81$ & $7.79-7.80$ & $7.73-7.80$ & $7.91-7.95$ \\
Arith. mean & 7.86 & 7.85 & 7.77 & 7.79 & 7.77 & 7.90 \\
Std. dev. & 0.03 & 0.02 & 0.04 & 0.01 & 0.02 & 0.04 \\
\hline \multicolumn{7}{|c|}{ S_InstFreq (kHz) } \\
\hline Min-max & $7.93-8.56$ & $7.71-8.47$ & $8.06-8.50$ & $8.22-8.37$ & $7.70-8.54$ & $8.10-8.20$ \\
Arith. mean & 8.26 & 8.18 & 8.29 & 8.26 & 8.28 & 8.16 \\
Std. dev. & 0.10 & 0.20 & 0.15 & 0.04 & 0.20 & 0.03 \\
\hline
\end{tabular}

Acoustic envelope (AE), also known as instantaneous amplitude, is defined by the trace and its Hilbert transform. It is a magnitude of the complex trace and reflects the energy of the signal. In general, amplitudes of $\mathrm{P}$ waves are much smaller than $\mathrm{S}$ waves (Fig. $4 \mathrm{a} \& 4 \mathrm{~b}$ ); however in $\mathrm{Pa}$ Fm considerable amplification of $\mathrm{P}$ wave compared to $\mathrm{S}$ wave is noticed. The greatest diversity of the instantaneous amplitudes of $\mathrm{P}$ and $\mathrm{S}$ waves is observed in Pe Fm where amplitudes of $\mathrm{P}$ and $\mathrm{S}$ waves can vary a lot. Ko Fm is characterized by the highest $\mathrm{S}$ wave energy and relatively low $\mathrm{P}$ wave amplitudes.

Frequency composition of acoustic signal is expressed by the dominant and instantaneous frequencies. The first one is computed as a maximum of the amplitude spectrum over a small window around the time sample. The latter is a rate of change of signal phase and is calculated from the complex trace. On the basis of the dominant frequency it can be concluded that $\mathrm{P}$ and $\mathrm{S}$ waves have visibly different frequency content (Fig. 4c \& 4d). P wave packets have higher frequencies then $\mathrm{S}$ wave. The frequency distribution over formations is clear and consistent. The lowest frequency of acoustic waves is observed in $\mathrm{Ja} \mathrm{Mb}$ whereas the highest frequencies are in Ko Fm. Pe Fm and Pa Fm are characterized by wide range of frequencies for $\mathrm{P}$ and $\mathrm{S}$ waves. Distribution of the instantaneous frequency is different (Tab. 1). $\mathrm{P}$ InstFreq has similar but much narrower range of values comparing to P_DomFreq. S_InstFreq presents significantly higher values than $\mathrm{S}$ _DomFreq, even higher than frequency of $\overline{\mathrm{P}}$ wave packets.

Figure 5 presents crossplots of selected attributes derived from acoustic full waveforms. Figure 5a shows dominant frequency of $\mathrm{P}$ and $\mathrm{S}$ waves. Carbonates (here Ko Fm), which 
are considered as rocks with high elastic parameters, have maintained high frequency. On the other hand $\mathrm{Ja} \mathrm{Mb}$ and $\mathrm{Sa} \mathrm{Fm}$ are characterized by lower dominant frequency. This may be related to the presence of organic matter (please compare Fig. 7c \& 7d). It can be noticed that there are some points with higher values of $\mathrm{P}_{-}$and $\mathrm{S}_{-}$DomFreq in Sa Fm (above the grey thicker lines that indicate average DomFreq in the whole investigated interval). These points correspond to the carbonate lamina within the Sa Fm.

Figure $5 \mathrm{~b}$ shows that siltstones and mudstones ( $\mathrm{Pa} \mathrm{Fm}$, Ja Mb, Pe Fm and part of $\mathrm{Sa}$ Fm) have high Poisson's ratio the higher Poisson's ratio is the lower elastic properties are. Limestones of Ko Fm have high Poissons's ratio but it is related to the mineral composition: calcite has higher $\mathrm{Vp} / \mathrm{Vs}$ ratio than quartz and thus increased Poisson's ratio [7]. Elastic properties are expressed here by the amplitude envelop of S wave (S_AE) the lower the amplitude envelope the lower the elastic properties.

Figure $5 \mathrm{c}$ confirms that weaker elastic properties (here represented by the S-wave impedance) decrease frequency of the acoustic wave. Ja $\mathrm{Mb}$ that is built of siltstones and mudstones with kerogen is characterized by the lowest dominant frequency and the lowest impedance. The highest frequency and impedance are observed in limestones of Ko Fm.

The last figure (Fig. 5d) reveals an interesting relation between instantaneous amplitudes of $\mathrm{P}$ and $\mathrm{S}$ waves. $\mathrm{S} \_\mathrm{AE}$ as a function of $\mathrm{AE}$ _P/S shows strong power relation. The higher elastic properties of the formation are the higher amplitudes of $\mathrm{S}$ wave and lower amplitudes of $\mathrm{P}$-wave (i.e. lower ratio of $\mathrm{P}$ and $\mathrm{S}$-waves $\mathrm{AE}$ ) are.
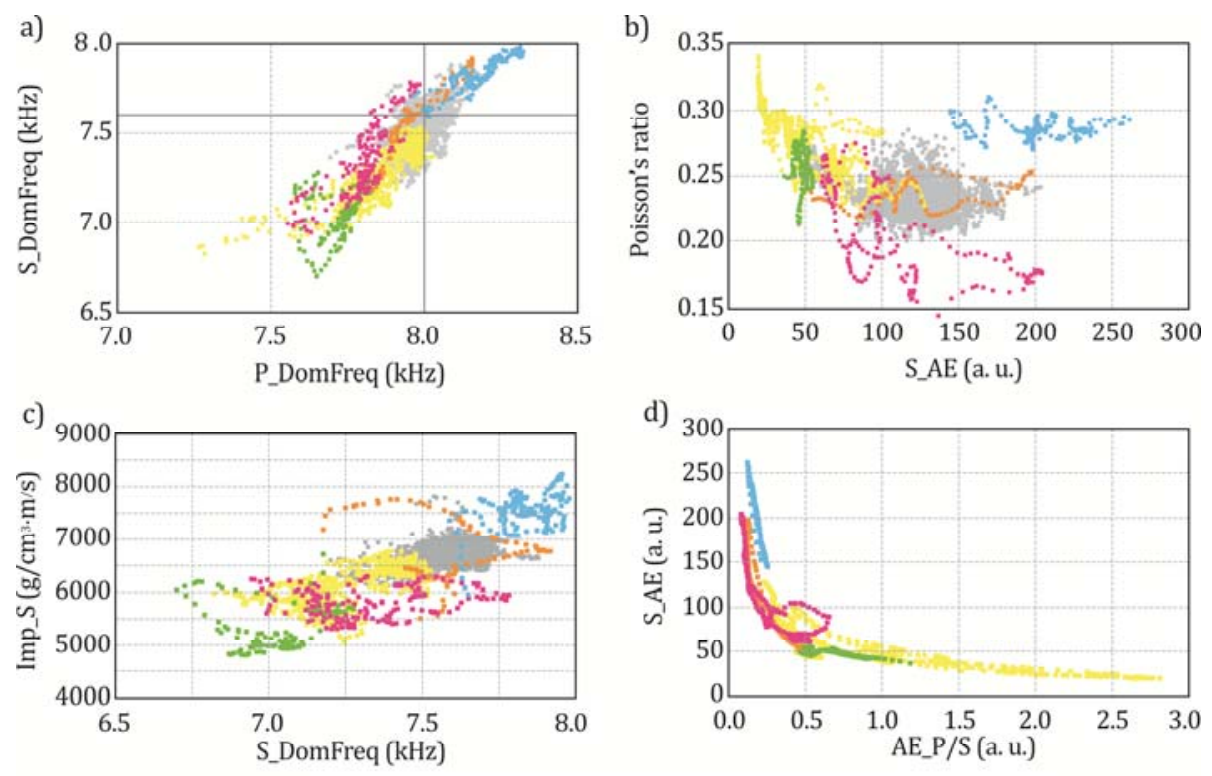

$\square$ Pe Fm $\square$ Pa Fm $\square \mathrm{Ja} \mathrm{Mb} \square$ PrFm $\square$ Sa Fm $\square$ Ko Fm

Fig. 5. Selected instantaneous attributes calculated from sonic logs for $\mathrm{P}$ and $\mathrm{S}$ waves in shale formations: relation between dominant frequency of $\mathrm{P}$ and $\mathrm{S}$ waves (a), Poissons's ratio as a function of amplitude envelope of S wave (b), correlation between impedance and dominant frequency of Swave (c), and power function between amplitude envelopes of $\mathrm{P}$ and $\mathrm{S}$ waves (d)

\subsection{Seismic attributes combined with attributes from acoustic log}

Due to different vertical resolutions of seismic data and well logs it was necessary to downscale attributes from sonic log. Seismic attributes after time-to-depth conversion were sampled 
with 4-m step interval. This is why the acoustic log attributes were smoothed in 4-m running window and interpolated to the seismic depth interval. Figure 6 shows resolution of seismic attributes, log data and the attributes after downscaling. It reduced significantly number of data in the crossplots (Fig. 7).

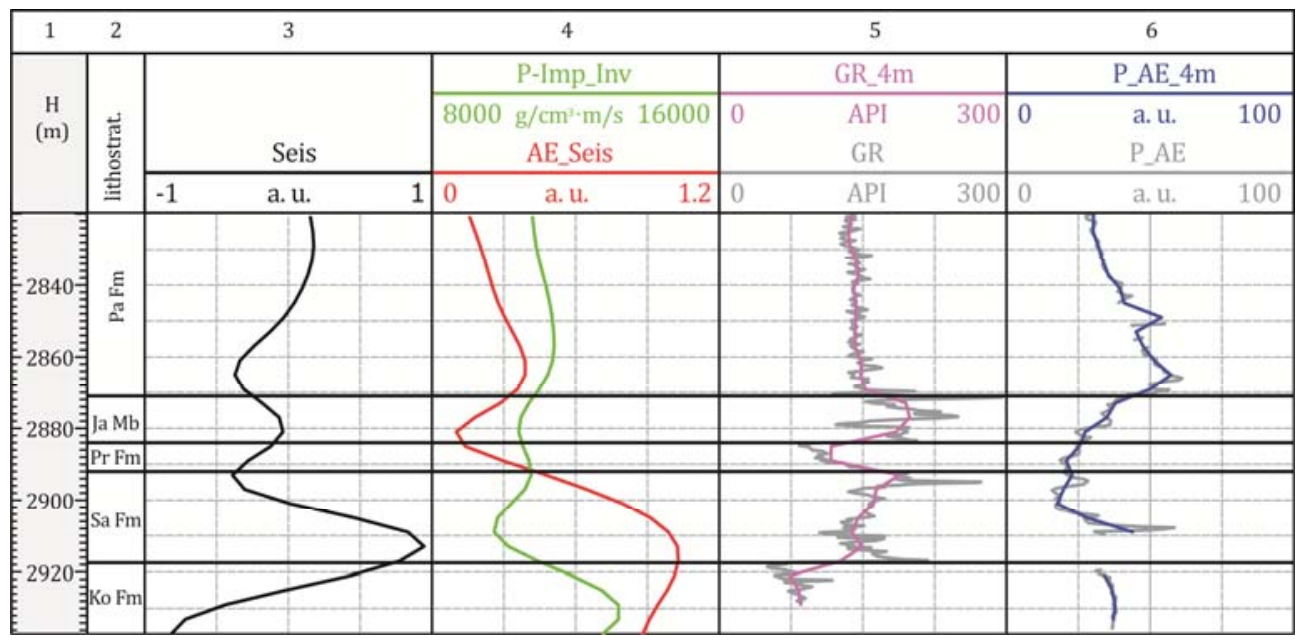

Fig. 6. Comparison of vertical resolution of seismic data ( 3 rd \& 4th tracks) with logging data (5th \& 6th tracks) before and after downscaling

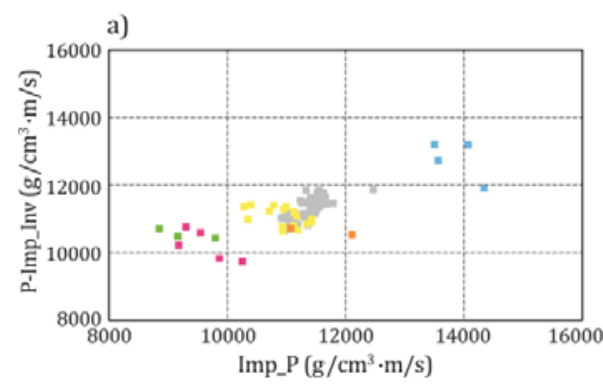

b)

c)
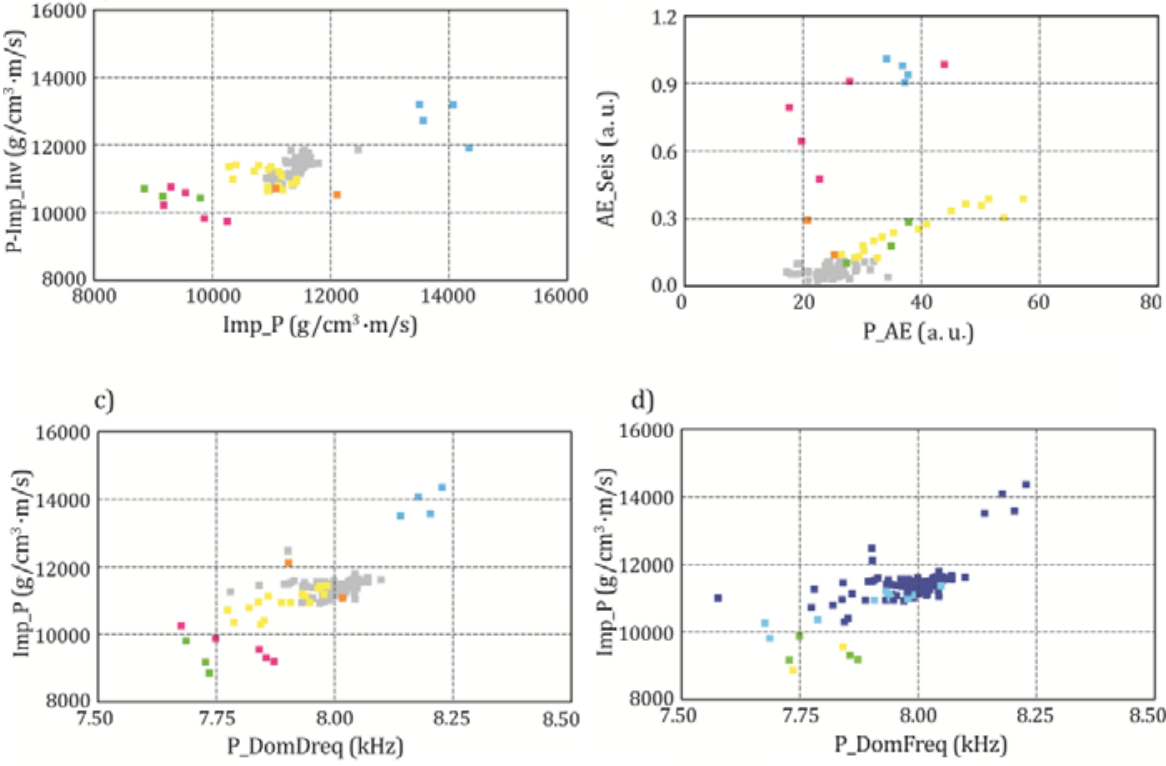

d)

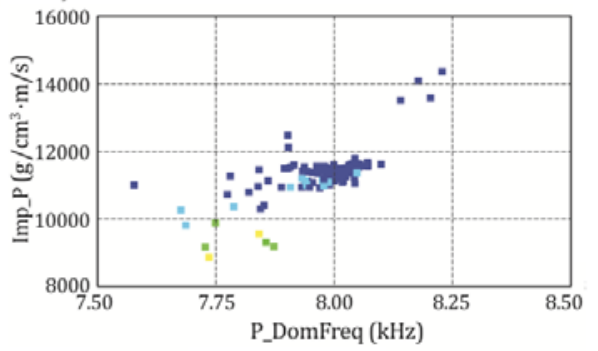

$\square \mathrm{PeFm} \square \mathrm{PaFm} \square \mathrm{Ja} \mathrm{Mb} \square \mathrm{PrFm} \square \mathrm{Sa} F m \quad \square$ Ko Fm

0

\begin{tabular}{lll}
\hline & l \\
v kerogen & 0.12
\end{tabular}

Fig. 7. Attributes from sonic log vs attributes from seismic data (a, b): comparison of impedance from $\log$ and seismic inversion (a), and amplitude envelope calculated from seismic trace and extracted Pwave packet from acoustic full waveform (b). Relation between dominant frequency of P wave and Pimpedance from sonic $\log (\mathrm{c})$ and the same relation as a function of volume of kerogen (d) 


\section{Summary}

Comparison of corresponding attributes from seismic and log data (Fig. 7a and b) shows that some of them represent the same information on the formation besides different scale of the measurements. For example, P-wave impedances from acoustic log and from seismic data are similar (Fig. 7a), though Imp_P has a bit higher values than P-Imp_Inv due to higher velocity of acoustic wave. The other attributes, such as AE of P-wave from sonic log and AE calculated from seismic trace (Fig. 7b) must be interpreted separately. AE of acoustic wave depends on the elastic properties of the some volume of the formation, whereas AE of seismic wave is a function of reflection coefficient at an interface between two layers with various impedances. Figure $7 \mathrm{c} \& 7 \mathrm{~d}$ shows approximately linear relation between P-impedance and dominant frequency of P-wave (both from sonic log) as a function of organic matter (volume of kerogen). The figures clearly show that presence of organic matter (i.e. elevated TOC content) decreases significantly elastic parameters of rocks it lowers density of the formation, velocity and frequency of acoustic waves.

\section{Acknowledgements}

This study was financed by The National Centre for Research and Development in the program Blue Gas, project: "Methodology to determine sweet spots based on geochemical, petrophysical and geomechanical properties in connection with correlation of laboratory test with well logs and generation model 3D" (MWSSSG) Polskie Technologie dla Gazu Łupkowego. Data for the study was allowed by Polish Oil and Gas Company, Warsaw, Poland. It was also financially supported by statutory funds No. 11.11.140.645 at AGH University of Science and Technology (AGH UST), Faculty of Geology, Geophysics and Environmental Protection (FGG\&EP), Krakow, Poland.

Author thanks Kamil Cichostępski for calculations of seismic attributes.

\section{References}

1. P. Poprawa, Shale gas potential of the Lower Palaeozoic complex in the Baltic and Lublin-Podlasie basins (Poland) (in Polish). Prz. Geol., 58, 3, 226-249 (2010)

2. J.A. Jarzyna, M. Bała, P.I. Krakowska, E. Puskarczyk, A. Strzępowicz, K. WawrzyniakGuz, D. Więcław, J. Ziętek, Shale Gas in Poland ((Ed.) InTech, 2007); Available from: https://www.intechopen.com/books/advances-in-natural-gas-emergingtechnologies/shale-gas-in-poland

3. K. Wawrzyniak-Guz, Acoustic Full Waveforms as a Bridge between Seismic Data and Laboratory Results in Petrophysical Interpretation, Acta Geophys., 64, 6, 2356-2381 (2016)

4. A.E. Barnes, Instantaneous spectral bandwidth and dominant frequency with applications to seismic reflection data, Geophysics, 58, 3, 419-428 (1993)

5. A.R. Brown, Understanding seismic attributes, Geophysics, 66, 1, 47-48 (2001)

6. M.T. Taner, Attributes revisited; Available from: http://www.rocksolidimages.com/attributes-revisited/ (2003)

7. J.H. Schön, Physical properties of rocks: fundamentals and principles of petrophysics (Elsevier, Amsterdam, 2004) 